\title{
SOX2 mediates crosstalk between Sonic Hedgehog and the Wnt/ $\beta$-catenin signaling pathway to promote proliferation of pituitary adenoma cells
}

\author{
JIAN TANG, LONGYI CHEN, ZHENYU WANG, GUANGFU HUANG and XIAO HU \\ Department of Neurosurgery, Sichuan Provincial People's Hospital, Chengdu, Sichuan 610072, P.R. China
}

Received April 28, 2016; Accepted May 14, 2018

DOI: $10.3892 / \mathrm{ol} .2019 .10311$

\begin{abstract}
The Sonic hedgehog (Shh) and Wnt/ $\beta$-catenin signaling pathways are important regulators of early tissue patterning and stem cell propagation, and aberrant regulation of these two signaling pathways has been associated with a number of types of cancer. The identification of adult stem cells in the pituitary raised the question of whether these two signaling pathways are involved in pituitary adenoma formation. In the present study, it was identified that treating a human pituitary adenoma cell line with Shh was not able to promote the proliferation of cancer cells, but Shh was able to upregulate the expression of sex-determining region $\mathrm{Y}$ box 2 (SOX2) which is characteristic of stem cells. The addition of Shh into $\beta$-catenin-expressing cells also promoted cell proliferation. On the other hand, addition of Wnt3a into or overexpression of $\beta$-catenin in SOX2-expressing cancer cells was able to promote cell proliferation, Further investigation revealed that SOX2 is required to mediate crosstalk between the Shh and $\mathrm{Wnt} / \beta$-catenin signaling pathways to promote the proliferation of pituitary adenoma cells.
\end{abstract}

\section{Introduction}

The anterior pituitary gland is a key regulator of the endocrine system. During life, it undergoes extensive remodeling in response to metabolic changes and is therefore prone to tumor formation. Pituitary tumors are benign neoplasms that may lead to marked morbidity owing to excess hormone secretion and/or compression of surrounding brain structures (1). Pituitary adenoma is formed by monoclonal proliferation of gland cells in the anterior pituitary $(2,3)$. Pathogenesis and effective treatment of pituitary adenoma have been widely explored, but the molecular mechanism is not fully understood.

Correspondence to: Dr Jian Tang, Department of Neurosurgery, Sichuan Provincial People's Hospital, 32 Yihuan Road, Chengdu, Sichuan 610072, P.R. China

E-mail: tangjiansc@sina.com

Key words: pituitary adenoma, Sonic Hedgehog, Wnt/ $\beta$-catenin, sex-determining region $\mathrm{Y}$ box 2, proliferation
Specific tumor-initiating and tumor-promoting factors have been characterized in animal models as well as in human tissue samples. In the last few years, the cancer stem cell (CSC) theory was introduced that states that a specific subpopulation of tumor cells possessing distinct stem cell properties by the expression of sex-determining region Y box 2 (SOX2), octamer-binding factor 4, Krüppel-like factor 4 and NANOG, is proposed to persist in tumors and lead to new tumors (4). The existence of CSCs in pituitary adenomas is controversial, but previous studies have demonstrated that a cluster of SOX2+ cells was able to maintain pituitary homeostasis and potentially contribute to pituitary tumors in a mice model $(5,6)$.

The Sonic hedgehog (Shh) signaling pathway is also involved in pituitary formation. Following the appearance of Rathke's pouch, Shh expression is excluded from this region, but remains in the surrounding areas (7). Furthermore, the Shh signaling pathway serves an important function in adult stem cell maintenance (8). Shh signaling pathway is frequently activated in several types of human cancer, and may contribute to tumorigenesis and progression by maintaining CSC character $(9,10)$.

The Wnt/ $\beta$-catenin signaling pathway serves a critical function in the control of cellular proliferation and differentiation during embryonic development and organogenesis (11). Deregulation of $\mathrm{Wnt} / \beta$-catenin signaling leads to pathological processes, including various types of cancer (12). In several types of cancer, aberrant $\mathrm{Wnt} / \beta$-catenin signaling is able to mediate CSCs to promote tumorigenesis. Previous studies have highlighted alterations of $\beta$-catenin in pituitary tumors $(13,14)$.

The aim of the present study was to investigate whether the Shh signaling pathway is able to initiate pituitary adenoma by regulating the character of CSCs. Single treatment with Shh or Wnt was not able to promote the proliferation of the pituitary adenoma cell line HP75. However, western blot analysis revealed that $\mathrm{Shh}$ triggered the upregulation of SOX2 which is characteristic of CSCs. The Wnt/ $\beta$-catenin signaling pathway was identified to promote the proliferation of SOX2-expressing cells. Inhibition of SOX2 expression disrupted the crosstalk between the Shh and Wnt/ $\beta$-catenin signaling pathways which inhibited cell proliferation. SOX2 was identified to promote the proliferation of pituitary adenoma cells by mediating crosstalk between the Shh and $\mathrm{Wnt} / \beta$-catenin signaling pathways. 


\section{Materials and methods}

Plasmids, short interfering RNA (siRNA) and transient transfection. The complete SOX2-coding sequence was amplified using the polymerase chain reaction (PCR) using primers 5'-GATCGCTAGCATGTACAACATGATGGAGAC GG-3' (forward) and 5'-GATCGCGGCCGCTCACATGTG TGAGAGGGGCAGTGTG-3' (reverse). cDNA from HP75 cells was used as template. Pfu DNA polymerase (Agilent Technologies, Inc., Santa Clara, CA, USA) was used for PCR according to the manufacturer's protocol. The thermocycling conditions for SOX 2 were: $95^{\circ} \mathrm{C}$ for $2 \mathrm{~min}$, and then 30 cycles of $95^{\circ} \mathrm{C}$ for $30 \mathrm{sec}$ and $60^{\circ} \mathrm{C}$ for $1 \mathrm{~min}$ and $72^{\circ} \mathrm{C}$ for $1 \mathrm{~min}$, final extension at $72^{\circ} \mathrm{C}$ for $5 \mathrm{~min}$ using the C1000-Touch Thermal Cycler (Bio-Rad Laboratories, Inc. Hercules, CA, USA). The complete $\beta$-catenin-coding sequence was amplified by PCR using primers 5'-GATCGCTAGCATGGCTACTCAAGC TGATTTGATGG-3' (forward) and 5'-GATCGCGGCCGC TTACAGGTCAGTATCAAACCAGGC-3' (reverse). The thermocycling conditions for $\beta$-catenin were: $95^{\circ} \mathrm{C}$ for $2 \mathrm{~min}$, and then 30 cycles of $95^{\circ} \mathrm{C}$ for $30 \mathrm{sec}$ and $60^{\circ} \mathrm{C}$ for $1 \mathrm{~min}$ and $72^{\circ} \mathrm{C}$ for $2 \mathrm{~min} 30 \mathrm{sec}$, final extension at $72^{\circ} \mathrm{C}$ for $5 \mathrm{~min}$ using the C1000-Touch Thermal Cycler (Bio-Rad Laboratories, Inc.). The PCR products were purified and cloned into $\mathrm{pCDH}$ lentivirus vector using NheI/NotI. Lipofectamine ${ }^{\mathrm{TM}} 2000$ (Invitrogen; Thermo Fisher Scientific, Inc., Waltham, MA, USA) was used to perform transient transfection according to the manufacturer's protocol.

The SOX2 RNAi sequence was 5'-GUUCUAGUGGUA CGGUAGG-3'. The scramble sequence was 5'-UCCUUGCUC CUUCGAAUGU-3'. Lipofectamine RNAiMAX (Invitrogen; Thermo Fisher Scientific, Inc.) was used to perform transient transfection of scramble siRNA or siRNA targeting SOX2 according to the manufacturer's protocol.

Cell culture and treatment. HP75 cells were purchased from the American Type Culture Collection (Manassas, VA, USA) and were routinely cultured in Dulbecco's modified Eagle's medium containing $15 \%$ horse serum, $2.5 \%$ fetal bovine serum, $0.05 \%$ glutamine, $100 \mu \mathrm{g} / \mathrm{ml}$ gentamicin and $100 \mathrm{IU} / \mathrm{ml}$ penicillin at $37^{\circ} \mathrm{C}$ in a humidified atmosphere containing $5 \%$ $\mathrm{CO}_{2}$. The cell line was passaged three times prior to use in the experiments.

For the proliferation assay, cells were seeded in 24-well plates and serum-starved for $24 \mathrm{~h}$, then cells were treated with Shh $(0.5,1$ or $5 \mu \mathrm{g} / \mathrm{ml}$; R\&D Systems, Inc., Minneapolis, MN, USA) or Wnt $3 a(5,10$ or $50 \mathrm{ng} / \mathrm{ml}$; R\&D Systems, Inc.) for $48 \mathrm{~h}$, using PBS as a negative control.

RNA extraction and reverse transcription (RT)-quantitative (q)PCR. Total RNA was extracted from HP75 cells using TRIzol $^{\circledR}$ reagent (Invitrogen; Thermo Fisher Scientific, Inc.), according to the manufacturer's protocol. cDNA was generated using an iScript cDNA synthesis kit (Bio-Rad Laboratories, Inc., Hercules, CA, USA), according to the manufacturer's protocol. SYBR-Green qPCR for GAPDH and SOX2 was performed using $\mathrm{iQ}^{\mathrm{TM}} \mathrm{SYBR}^{\circledast}$ Green Supermix following manufacturer's protocol (Bio-Rad Laboratories, Inc.). The thermocycling conditions were: $95^{\circ} \mathrm{C}$ for $3 \mathrm{~min}$, and then 40 cycles of $95^{\circ} \mathrm{C}$ for $15 \mathrm{~s}$ and $60^{\circ} \mathrm{C}$ for $1 \mathrm{mi}$ using the CFX 96 realtime PCR machine (Bio-Rad Laboratories, Inc.). Primers for SOX2 were 5'-GGGAAATGGGAGGGGTGCAAAAGA GG-3' (forward) and 5'-TTGCGTGAGTGTGGATGGGAT TGGTG-3' (reverse). Primers for GAPDH were 5'-TTCCAA TATGATTCCACCCA-3' (forward) and 5'-ATGACAAGC TTCCCGTTCTC-3' (reverse).

Western blotting. HP75 cells were harvested following the indicated treatment and lysed in SDS sample buffer. The protein concentration determination was performed using a BCA kit (Pierce; Thermo Fisher Scientific, Inc.) according to the manufacturer's protocol. Samples $(50 \mu \mathrm{g})$ were loaded per lane. Polyacrylamide gels (4-12\%) were used and the proteins in the gels were transferred onto PVDF membranes (Bio-Rad Laboratories, Inc.). The membranes were blocked with 5\% non-fat milk in TBST (TBS with $0.05 \%$ Tween 20 ) for $1 \mathrm{~h}$ at room temperature, and the indicated primary antibodies were incubated shaking slowly overnight at $4^{\circ} \mathrm{C}$. Membranes were washed in TBST 10 min 3 times and incubated with secondary antibody for $1 \mathrm{~h}$ at room temperature, then membranes were washed in TBST 10 min 3 times. Antibodies used were anti-Ptch1 (sc-518044) (1:200; Santa Cruz Biotechnology, Inc.), anti-SMO (sc-166685) (1:100; Santa Cruz Biotechnology, Inc.), anti-Gli1 (sc-6152) (1:100; Santa Cruz Biotechnology,Inc.), anti-SOX2 (sc-365964) (1:100; Santa Cruz Biotechnology, Inc.), anti-Frizzled (sc-398082) (1:200; Santa Cruz Biotechnology, Inc.), anti-Dsh (sc-8025) (1:500; Santa Cruz Biotechnology, Inc.), anti-phospho- $\beta$-catenin (sc-57535) (1:500; Santa Cruz Biotechnology, Inc.), anti- $\beta$-catenin (sc-59737) (1:500; Santa Cruz Biotechnology, Inc.). Secondary antibodies were: Donkey anti-rabbit, horseradish peroxidase (HRP)-conjugate (sc-2313); donkey anti-mouse, HRP-conjugate (sc-2314); and donkey anti-goat, HRP-conjugate (sc-2020) (1:5,000; Santa Cruz Technology, Inc.). Detection was performed using an enhanced chemiluminescence kit (Pierce; Thermo Fisher Scientific, Inc.) according to the manufacturer's protocol. $\beta$-actin (sc-47778) (1:5,000; Santa Cruz Biotechnology, Inc.) was used as a loading control.

Cell proliferation assay. Cell proliferation was determined by cell counting. Briefly, cells were seeded in 24-well plates at low density $\left(5 \times 10^{4}\right)$ and cultured overnight. Cells were incubated with/without the indicated reagent and cultured for $48 \mathrm{~h}$, trypsinized and resuspended in PBS, and finally stained with trypan blue. Viable cells were counted using a hemocytometer at x100 magnification under a light microscope.

Statistical analysis. Statistical analysis was performed using GraphPad Prism (version 6.0; GraphPad Software, Inc., La Jolla, CA, USA). For multiple comparisons, analysis of variance with Bonferroni's post hoc test was applied. Results are presented as the mean \pm standard error of the mean (SEM). All experiments were repeated at least three times with reproducible results. $\mathrm{P}<0.05$ was considered to indicate a statistically significant difference.

\section{Results}

Activation of the Shh signaling pathway does not promote proliferation of pituitary adenoma cells. To investigate the 
$\mathbf{A}$

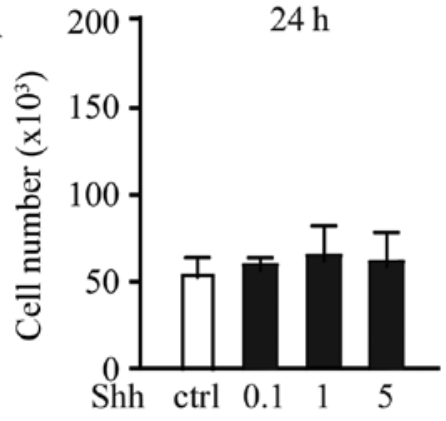

B

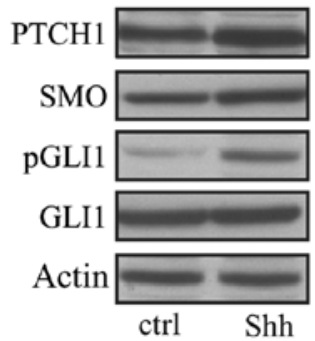

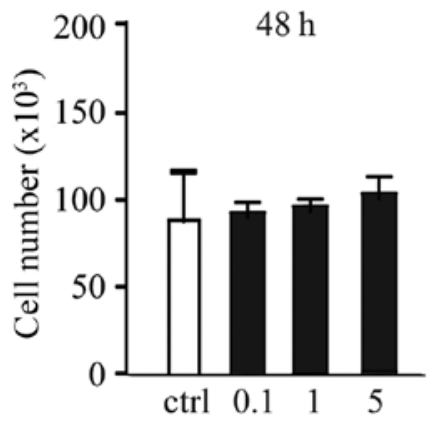

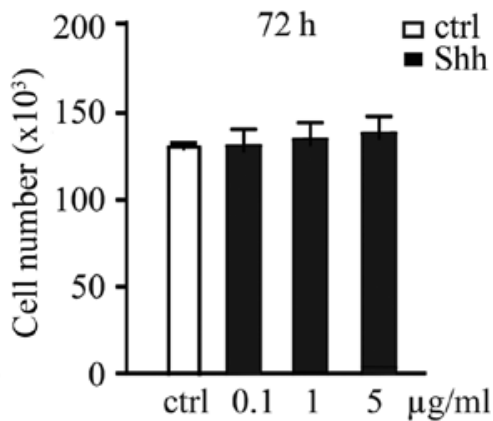

C

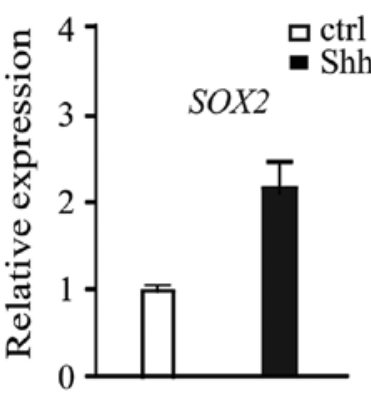

D

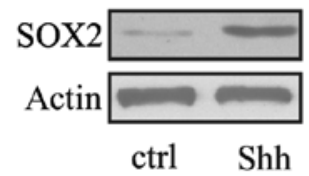

Figure 1. Activation of the Shh signaling pathway only has no effect on the proliferation of pituitary adenoma cells. (A) HP75 cells were treated with PBS (ctrl) or Shh recombinant protein, and a proliferation assay was performed. (B) Western blot analysis of the activation of Shh signaling pathway proteins in HP75 cells following treatment with PBS (ctrl) or Shh. Expression of SOX2 was analyzed using (C) the quantitative polymerase chain reaction and (D) western blotting. Shh, Sonic Hedgehog; SOX2, sex-determining region Y box 2; p-, phospho-; ctrl, control; NS, not significant.
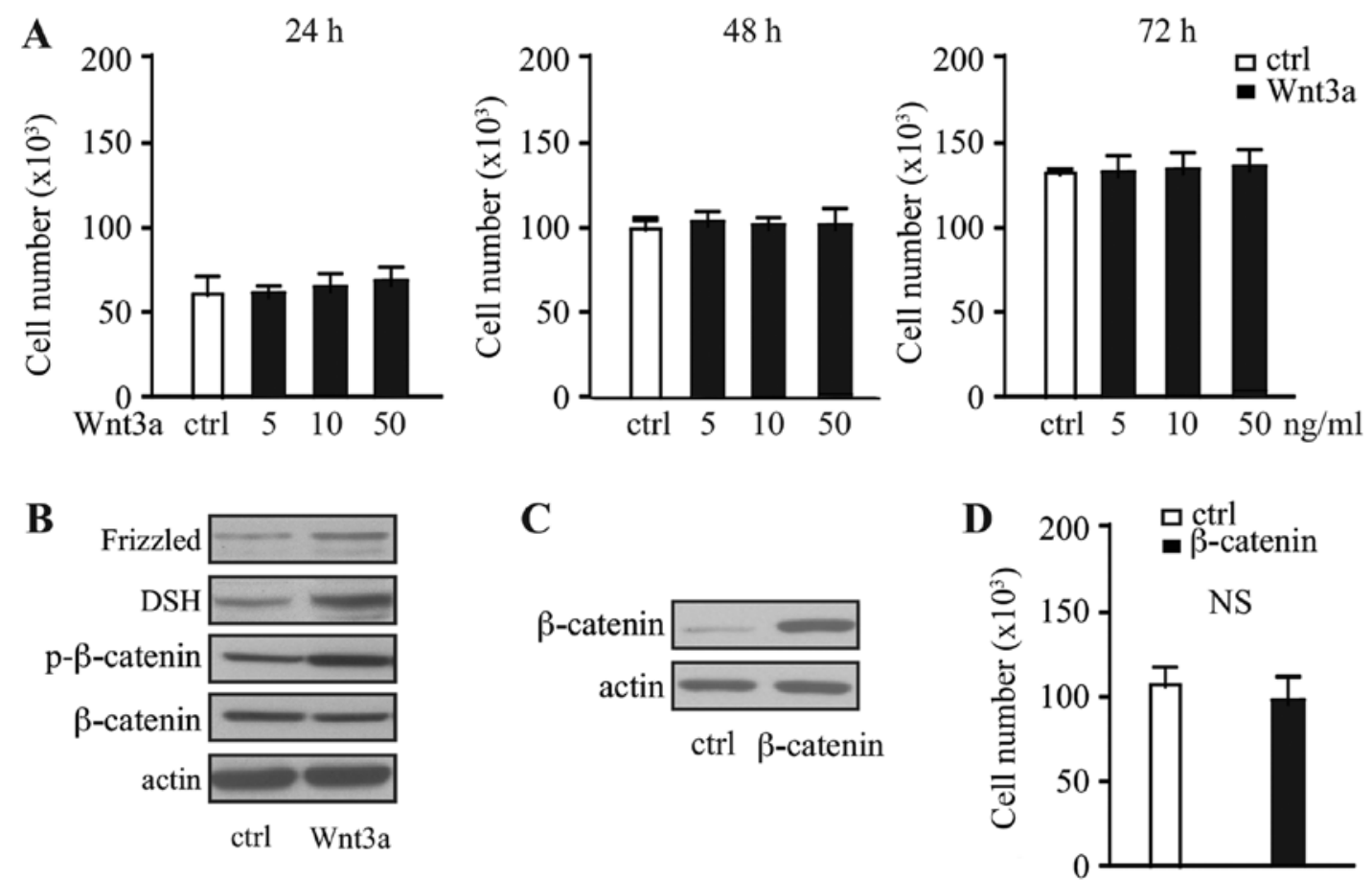

Figure 2. Activation of the Wnt/ $\beta$-catenin signaling pathway only does not promote the proliferation of pituitary adenoma cells. (A) HP75 cells were treated with PBS (ctrl) or Wnt3a recombinant protein, and a proliferation assay was performed. (B) Western blot analysis of the activation of Wnt signaling pathway proteins in HP75 cells following treatment with PBS (ctrl) or Wnt3a. (C) Ectopic expression of $\beta$-catenin was analyzed using western blotting, and (D) a proliferation assay was performed. ctrl, control; NS, not significant.

effect of Shh signaling on the progression of pituitary adenoma, the human pituitary adenoma cell line HP75 was treated with different concentrations of recombinant Shh for 24,48 or 72 . Shh was identified to have no significant effect on cell proliferation regardless of the concentration or duration (Fig. 1A).
Western blot analysis identified that HP75 cells express Ptch1, SMO and Gli1 following Shh treatment (Fig. 1B). The expression of the stem cell marker SOX2 was investigated, and it was identified that Shh upregulated the expression of SOX2 at the mRNA (Fig. 1C) and protein level (Fig. 1D). Therefore, 

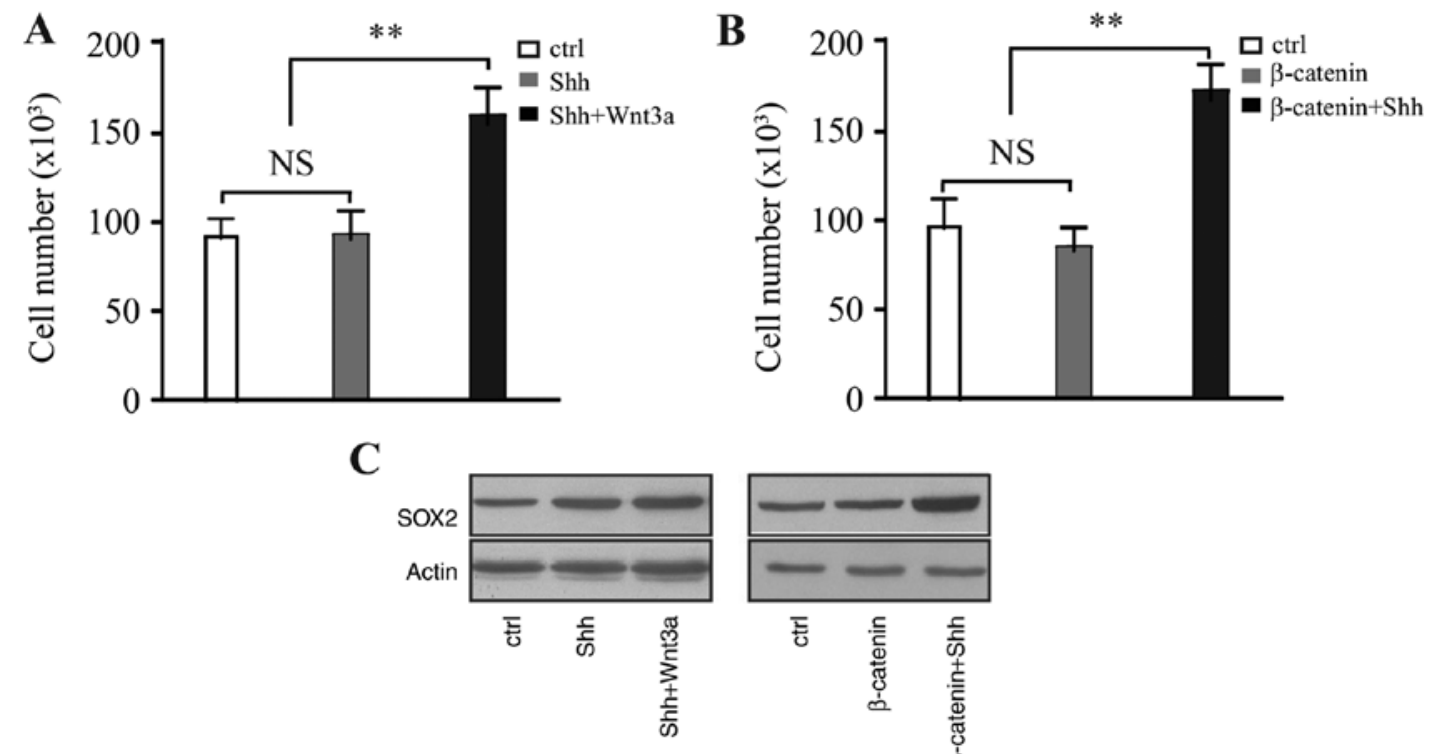

Figure 3. Crosstalk between the Shh and Wnt/ $\beta$-catenin signaling pathways leads to the proliferation of pituitary adenoma cells. (A) HP75 cells were treated with PBS or Shh recombinant protein or Shh+Wnt3a for $48 \mathrm{~h}$, and a proliferation assay was performed. (B) $\beta$-catenin-expressing HP75 cells were treated with PBS or Shh recombinant protein for $48 \mathrm{~h}$, and a proliferation assay was performed. ${ }^{* *} \mathrm{P}<0.01$. (C) Western blot analysis of the expression of SOX2 in HP75 cells. Shh, Sonic Hedgehog; SOX2, sex-determining region Y box 2; ctrl, control.

$\mathbf{A}$

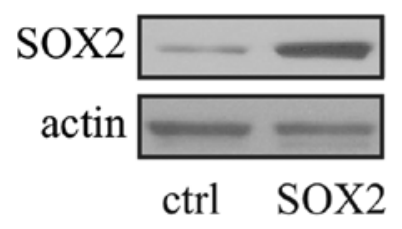

C

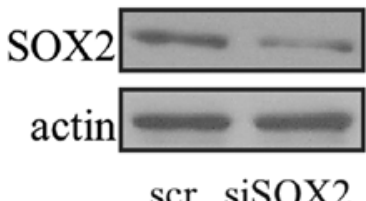

B

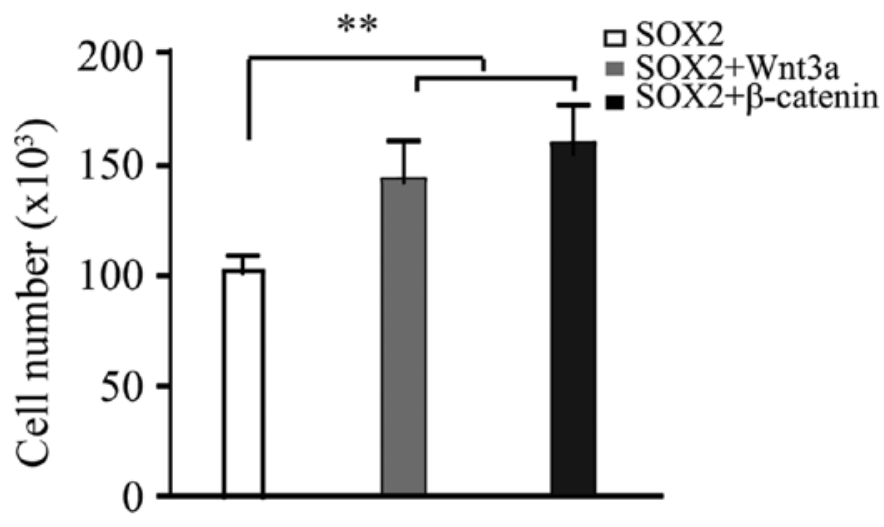

D

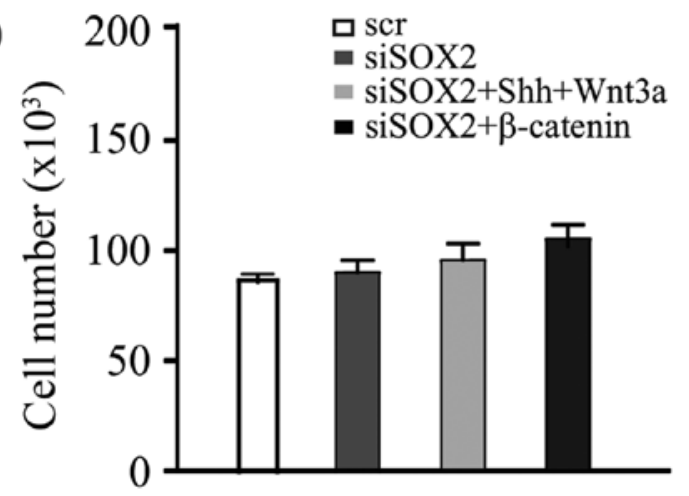

Figure 4. SOX2 is required to mediate crosstalk between Shh and Wnt/ $\beta$-catenin signaling pathways to promote proliferation of pituitary adenoma cells. (A) Western blot analysis identified the ectopic expression of SOX2 in HP75 cells. (B) SOX2-expressing cells were treated with PBS (ctrl) or Wnt3a recombinant protein or overexpression of $\beta$-catenin for $48 \mathrm{~h}$, and a proliferation assay was performed. (C) Western blot analysis of the expression of SOX 2 in $\mathrm{HP} 75$ cells. (D) SOX2-depleted cells were treated with PBS or Shh+Wnt3a recombinant protein or overexpression of $\beta$-catenin for $48 \mathrm{~h}$, and a proliferation assay was performed. ${ }^{* *} \mathrm{P}<0.01$. SOX2, sex-determining region Y box 2; Shh, Sonic Hedgehog; ctrl, control; scr, scrambled; si, short interfering.

activation of the Shh signaling pathway only was identified to have no effect on pituitary adenoma cell proliferation.
Activation of the Wnt/ $\beta$-catenin signaling pathway does not promote proliferation of pituitary adenoma cells. To 
investigate the effect of Wnt signaling on the progression of pituitary adenoma, the human pituitary adenoma cell line HP75 was treated with different concentrations of recombinant Wnt3a for 24, 48 or $72 \mathrm{~h}$. Wnt3a was identified to have no significant effect on the cell proliferation regardless of concentration or duration (Fig. 2A). Western blot analysis identified that HP75 cells express Frizzled, Dsh and $\beta$-catenin, with phosphorylation of $\beta$-catenin following Wnt3a treatment (Fig. 2B). Following overexpression of $\beta$-catenin in HP75 cells, consistent with Wnt3a treatment (Fig. 2C), no effect on cell proliferation was observed (Fig. 2D). Therefore, activation of the Wnt signaling pathway only was identified to have no effect on pituitary adenoma cell proliferation.

Crosstalk between Shh signaling and Wnt/ $\beta$-catenin signaling leads to proliferation of pituitary adenoma cells. HP75 cells were treated with recombinant Shh. After $48 \mathrm{~h}$, cells were washed with PBS and then treated with Wnt3a for a further $48 \mathrm{~h}$. Wnt3a treatment significantly promoted cell proliferation (Fig. 3A). Furthermore, treatment of $\beta$-catenin-overexpressing cells with different concentrations of Shh also promoted cell proliferation (Fig. 3B). Western blot analysis identified that the expression of SOX2 is upregulated in these cells (Fig. 3C). Therefore, crosstalk between the Shh and Wnt/ $\beta$-catenin signaling pathways was identified to promote proliferation of pituitary adenoma cells.

SOX2 is required to mediate crosstalk between the Shh and Wnt/ $\beta$-catenin signaling pathways. SOX2 was overexpressed in HP75 cells (Fig. 4A) and cells were treated with Wnt3a. Wnt3a was identified to significantly promote proliferation of SOX2-expressing cells, and, consistently, overexpression of $\beta$-catenin in SOX2-expressing cells also promoted cell proliferation (Fig. 4B). The expression of SOX2 was knocked down in HP75 cells (Fig. 4C), and cells were treated sequentially with Shh and Wnt3a. The results identified that, without expression of SOX2, sequential treatment with Shh and Wnt3a was not able to promote cell proliferation; furthermore, overexpression of $\beta$-catenin in SOX2-knockdown cells was not able to promote cell proliferation (Fig. 4D). Therefore, it is hypothesized that proliferation of pituitary adenoma cells depends on the crosstalk between the Shh and Wnt/ $\beta$-catenin signaling pathways which is mediated by SOX2.

\section{Discussion}

CSCs are hypothesized to be the cell-of-origin of various types of tumor. It has been demonstrated that CSCs act in a cell-autonomous manner (15). The existence and the function of CSCs in benign pituitary adenomas is a matter of controversy. It has been identified that isolation of sphere-forming stem-like cells from pituitary tumors may lead to the production of pituitary hormone-secreting cell types. Pituitary adenomas may be derived from a source of pituitary progenitor cells (16).

The Shh signaling pathway serves a crucial function in fetal development, and in tumorigenesis and progression. Shh signaling is reported to contribute to tumorigenesis through maintaining CSC characteristics (9). The Shh pathway has previously been demonstrated to be markedly associated with pituitary adenoma (17). In the present study, it was demonstrated that Shh was able to upregulate the expression of SOX2 in pituitary cancer cells, but was not able to promote proliferation in vitro. Therefore, activation of Shh only is not sufficient to promote pituitary adenoma progression.

In the present study, using biochemical and genetic approaches, it was demonstrated that SOX2 was able to promote the proliferation of pituitary adenoma cells via mediating crosstalk between the Shh and Wnt/ $\beta$-catenin signaling pathways.

SOX2 was identified to be a key marker of adult stem cells in various tissues including the pituitary tissue. SOX $2^{+}$ cells in mouse pituitary was identified to be multipotent and able to self-renew and differentiate into any other endocrine cell types of the pituitary gland (18). Previous studies identified that $\mathrm{SOX} 2^{+}$cells contributed to pituitary tumorigenesis following co-activation of the Wnt/ $\beta$-catenin signaling pathway in vivo $(13,14)$. In agreement, the results of the present study identified that activation of $\beta$-catenin in $\mathrm{SOX} 2^{+}$cancer cells was able to promote proliferation of cancer cells.

In summary, the results of the present study identified that treatment with Shh was not able to promote proliferation of pituitary adenoma cells. However, western blot analysis demonstrated that Shh triggered the upregulation of SOX2 which is a CSC characteristic. The Wnt/ $\beta$-catenin signaling pathway was demonstrated to promote the proliferation of SOX2-expressing cells. Inhibition of SOX2 expression disrupted the crosstalk between the Shh and $\mathrm{Wnt} / \beta$-catenin signaling pathways which inhibited cell proliferation. Therefore, SOX2 was identified to promote the proliferation of pituitary adenoma cells through mediating crosstalk between the Shh and Wnt/ $\beta$-catenin signaling pathways.

\section{Acknowledgements}

Not applicable.

\section{Funding}

No funding was received.

\section{Availability of data and materials}

The datasets used and/or analyzed during the current study are available from the corresponding author on reasonable request.

\section{Authors' contributions}

JT conceived and conducted the experiment. LC and ZW participated in acquiring the data. $\mathrm{GH}$ and $\mathrm{XH}$ performed the statistical analysis and drifted the manuscript.

\section{Ethics approval and consent to participate}

Not applicable.

\section{Patient consent for publication}

Not applicable. 


\section{Competing interests}

The authors declare that they have no competing interests.

\section{References}

1. Asa SL and Ezzat S: The pathogenesis of pituitary tumors. Annu Rev Pathol 4: 97-126, 2009.

2. Gueorguiev M and Grossman AB: Pituitary tumors in 2010: A new therapeutic era for pituitary tumors. Nat Rev Endocrinol 7: 71-73, 2011.

3. Melmed S: Pathogenesis of pituitary tumors. Nat Rev Endocrinol 7: 257-266, 2011.

4. Mathieu J, Zhang Z, Zhou W, Wang AJ, Heddleston JM, Pinna CM, Hubaud A, Stadler B, Choi M, Bar M, et al: HIF induces human embryonic stem cell markers in cancer cells. Cancer Res 71: 4640-4652, 2011.

5. Florio T: Adult pituitary stem cells: From pituitary plasticity to adenoma development. Neuroendocrinology 94: 265-277, 2011.

6. Castinetti F, Davis SW, Brue T and Camper SA: Pituitary stem cell update and potential implications for treating hypopituitarism. Endocr Rev 32: 453-471, 2011.

7. Ezzat S, Asa SL, Couldwell WT, Barr CE, Dodge WE, Vance ML and McCutcheon IE: The prevalence of pituitary adenomas: A systematic review. Cancer 101: 613-619, 2004.

8. Briscoe $\mathrm{J}$ and Thérond PP: The mechanisms of hedgehog signalling and its roles in development and disease. Nat Rev Mol Cell Biol 14: 416-429, 2013

9. Treier M, O'Connell S, Gleiberman A, Price J, Szeto DP, Burgess R, Chuang PT, McMahon AP and Rosenfeld MG: Hedgehog signaling is required for pituitary gland development. Development 128: 377-386, 2001.
10. Xie J, Bartels CM, Barton SW and Gu D: Targeting hedgehog signaling in cancer: Research and clinical developments. Onco Targets Ther 6: 1425-1435, 2013.

11. Clevers H: Wnt/beta-catenin signaling in development and disease. Cell 127: 469-480, 2006.

12. Grigoryan T, Wend P, Klaus A and Birchmeier W: Deciphering the function of canonical Wnt signals in development and disease: Conditional loss- and gain-of-function mutations of beta-catenin in mice. Genes Dev 22: 2308-2341, 2008.

13. Gaston-Massuet C, Andoniadou CL, Signore M, Jayakody SA, Charolidi N, Kyeyune R, Vernay B, Jacques TS, Taketo MM, Le Tissier P, et al: Increased Wingless (Wnt) signaling in pituitary progenitor/stem cells gives rise to pituitary tumors in mice and humans. Proc Natl Acad Sci USA 108: 11482-11487, 2011.

14. Andoniadou CL, Matsushima D, Mousavy Gharavy SN, Signore M, Mackintosh AI, Schaeffer M, Gaston-Massuet C, Mollard P, Jacques TS, Le Tissier P, et al: Sox2(+) stem/progenitor cells in the adult mouse pituitary support organ homeostasis and have tumor-inducing potential. Cell Stem Cell 13: 433-445, 2013.

15. Frank NY, Schatton T and Frank MH: The therapeutic promise of the cancer stem cell concept. J Clin Invest 120: 41-50, 2010.

16. Nassiri F, Cusimano M, Zuccato JA, Mohammed S, Rotondo F, Horvath E, Syro LV, Kovacs K and Lloyd RV: Pituitary stem cells: Candidates and implications. Pituitary 16: 413-418, 2013.

17. Gomes DC, Jamra SA, Leal LF, Colli LM, Campanini ML, Oliveira RS, Martinelli CE Jr, Elias PC, Moreira AC, Machado HR, et al: Sonic Hedgehog pathway is upregulated in adamantinomatous craniopharyngiomas. Eur J Endocrinol 172: 603-608, 2015.

18. Fauquier T, Rizzoti K, Dattani M, Lovell-Badge R and Robinson IC: SOX2-expressing progenitor cells generate all of the major cell types in the adult mouse pituitary gland. Proc Natl Acad Sci USA 105: 2907-2912, 2008. 